\title{
Innovating agriculture: Growing small ideas into game-changers
}

Last update: 2 March 2017

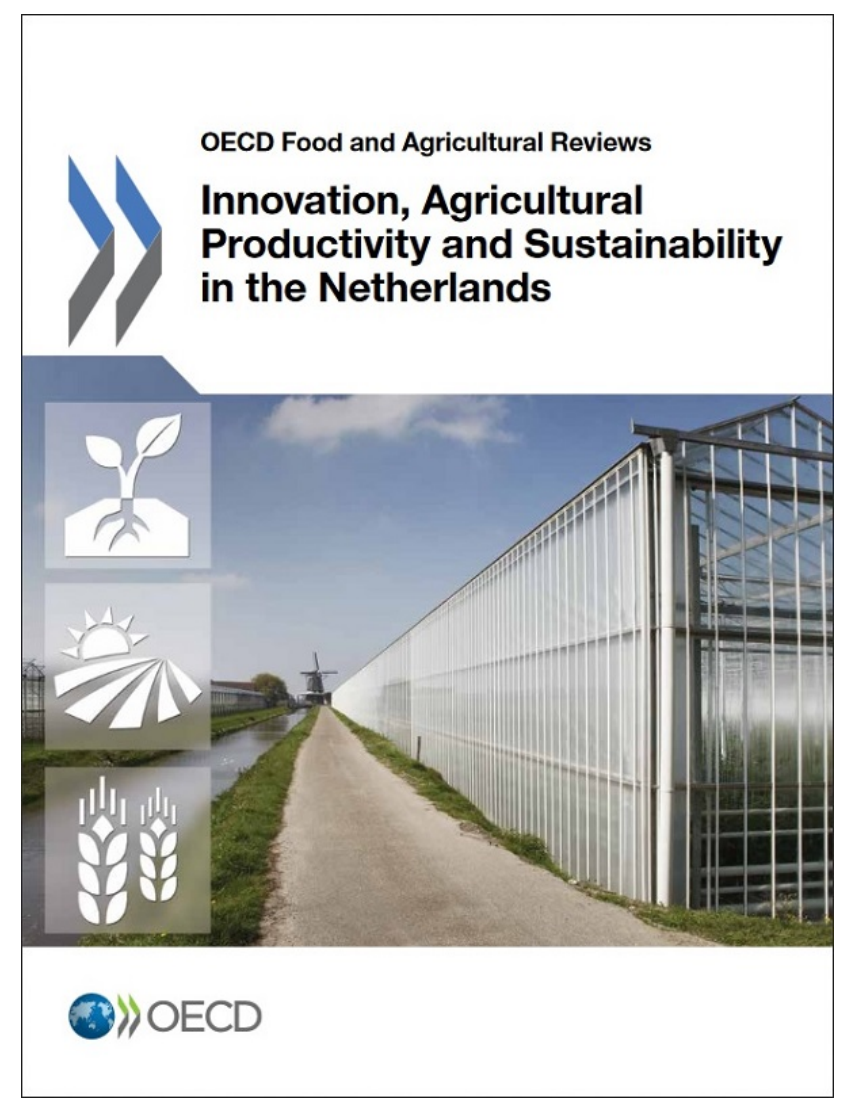

"Necessity is the mother of invention" is an oft-repeated phrase that is highly relevant to agricultural systems today. Growing global demand for food, fuel and fibre will have to be met by improving agricultural productivity growth, which will be a tall order, given increasing pressures on natural resources, resulting from climate change and competition for land, for instance. Any growth in agriculture will therefore have to be achieved sustainably through more efficient resource use.

Effective agricultural knowledge and innovation systems can go a long way towards addressing these challenges. A new OECD book series, Innovation, Agricultural Productivity and Sustainability, explores the relationships between 
innovation, productivity and sustainability in individual countries, and examines the respective roles of the government and private sector in strengthening agricultural innovation systems and facilitating their adoption at farm and agrifood firm levels. The series explores the conditions in which food and agriculture businesses in Australia, Brazil, Canada and the Netherlands innovate in order to become more productive and environmentally sustainable. Factors influencing innovation are examined: economic stability, governance and trust in institutions; a favourable and predictable environment for investment; capacities and public services enabling business development; as well as an effective agricultural policy and the operation of agricultural innovation systems.

The studies find strengths and weaknesses in the four countries examined. While the policy environment in the Netherlands is one of the most favourable to innovation investment, there is room for improvement, including in access to capital for small and medium-sized enterprises, and levels of public funding for research and education institutions. The agriculture and agro-processing sectors in Brazil, meanwhile, have demonstrated impressive growth thanks to productivity improvements and new technologies, but a number of obstacles remain, including framework conditions for innovation. Although the overall policy framework in Australia is supportive of innovation, agribusiness currently underinvests in rural $R \& D$, perhaps due to public overinvestment in applied research. And finally, while the general policy environment in Canada is conducive to the investment necessary for productivity growth, the enabling environment for productivity- and sustainability-oriented innovation could be improved, the report finds.

Three more titles in this series are expected in 2016, covering China, Turkey and the US.

See www.oecd-ilibrary.org/fr/agriculture-and-food/oecd-food-and-agriculturalreviews_24114278 